\title{
Henoch-Schönlein purpura without systemic involvement beginning with acute scrotum and mimicking torsion of testis
}

\author{
Levent Verim $^{1}$, Filiz Cebeci ${ }^{2}$, M. Remzi Erdem ${ }^{3}$, Adnan Somay ${ }^{4}$ \\ ${ }^{1}$ Departments of Urology and ${ }^{2}$ Dermatology, Haydarpasa Numune Training Hospital, Istanbul, Turkey; \\ ${ }^{3}$ Department of Urology, Bezmialem Vakif University, Istanbul, Turkey; \\ ${ }^{4}$ Department of Pathology, Fatih Sultan Mehmet Research and Teaching Hospital, Istanbul, Turkey.
}

\begin{abstract}
Fenoch-Schönlein purpura (HSP) is the most common systemic vasculitis in children. Summary Typical presentations of HSP are palpable purpura of the small vessels in the hips and lower limbs, abdominal pain, arthritis, and hematuria. Scrotal involvement manifested by the presence of scrotal pain and swelling during the course of the disease is rarely seen. HSP without systemic involvement with acute scrotum mimicking testicular torsion is even rare in the medical literature. In most cases, patients with this disease achieve complete recovery. Herein, we report an interesting HSP case with skin symptoms but without systemic involvement and then progression to acute scrotum resembling torsion of testis.
\end{abstract}

KEY WORDS: Schönlein purpura; Non-systemic involvement; Scrotal swelling; Torsion of testis.

\section{INTRODUCTION}

Henoch-Schönlein purpura generally resolves without permanent complications. However, serious gastrointestinal (GI) and renal complications may occur. The involvement of male gentalia presenting as the only initial manifestation of HSP is so unusual that the diagnosis can easily be missed. In the literature, a limited number of cases have been reported in which acute scrotum was the initial presenting symptom in patients affected by HSP (1). Herein, we report an interesting case who had HSP and subsequently developed acute scrotum resembling torsion of testis while receiving beta-lactam antibiotic and paracetamol therapy because of acute tonsillitis.

\section{Case report}

A 5-year-old boy was referred to our pediatric emergency room by his parents with a complaint of acute swelling and pain of the left testis. The patient had an acute tonsillitis one week ago and then, purpuric skin rash appeared at his lower extremities, hips and, genital region while receiving beta-lactam antibiotic and paracetamol. The parents did not describe of any insect bite or vaccination during the previous 3 months. Acute scrotal swelling developed just before his application to our hospital. Urgent urologic consultation was asked for the suspicion of testicular torsion. The patient was anxious and had erythematous-purpuric dermal lesions on the left lower limb, groins and scrotum when we observed him (Figure 1). His left testis was lifted upwards in the scrotum and very tender on palpation. Lifting the testes didn't enhance the pain. The child voided without difficulty although edema of prepuce and had no gross hematuria or cloudy urine. There was no microscopic hematuria or pyuria in urinalysis and complete blood count $(\mathrm{CBC})$ and blood chemistry data were within normal limits, but erythrocyte sedimentation rate (ESR) was $20 \mathrm{~mm} /$ hour (normal value $0-15$ ) and C-reactive protein was $15 \mathrm{mg} / \mathrm{dl}$ (normal value 0-59). His stool occult blood test was negative. There was no hepatosplenomegaly (HSM) at the abdominal ultrasonography imaging. Bilateral painful and erythematous scrotal swelling with scrotal wall thickening was established at the physical examination. A hypoechoic and heterogeneous C-shaped lesion, 
Figure 1.

Wiev of the erythamatous-purpuric dermal lesions after orchitis.

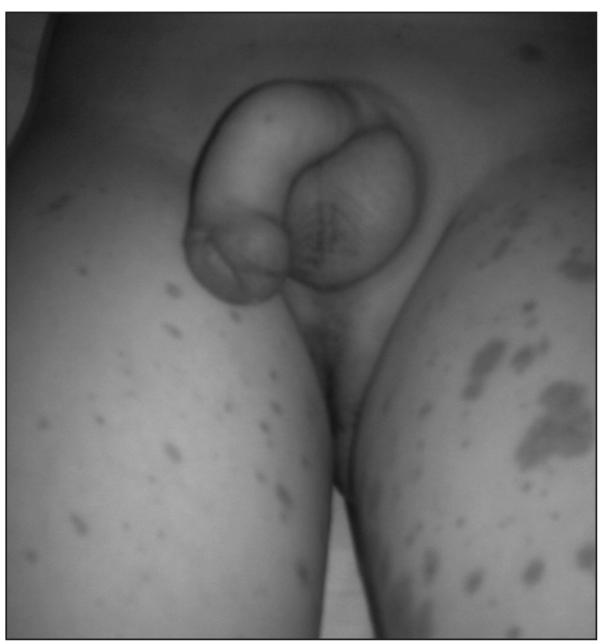

Figure 3.

Skin biopsy from the scrotum revealed massive perivascular cell infiltrate composed of neutrophils in the upper and mid-dermis, which was associated with extravasated erythrocytes. H\&Ex100.

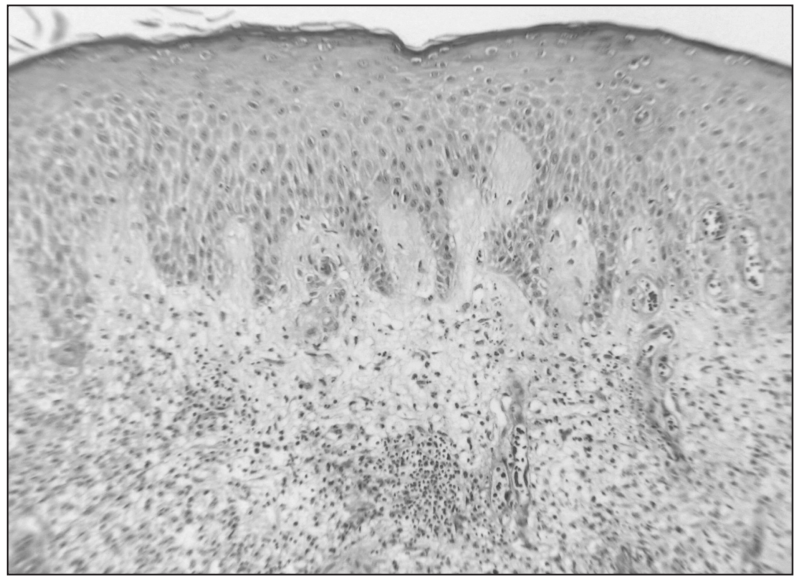

(7 mm x $24 \mathrm{~mm}$ in size) was found between the left testis and the enlarged left epididymis at scrotal ultrasound examination (Figure 2). Blood flow of testes was within normal sequence at color Doppler ultrasonography. We ruled out the torsion of the testis and diagnosed a simple epididymoorchitis. The patient was refered to dermatologist for evaluation of skin lesion. The patient was recognized and hospitalized by dermatologist as HSP without systemic involvement. Skin biopsy from the scrotum revealed massive perivascular cell infiltrate composed of neutrophils in the upper and mid-dermis, which was associated with nuclear dust, necrosis of endothelial cells and fibrinoid degeneration (Figure 3-4). IgA deposition was observed along the small blood vessel walls in the upper dermis by direct immunofluorescence staining (leucocytoclastic vasculitis).

Wide-spectrum antibiotic and, low dose (1,5 mg/kg/day)
Figure 2.

wiev of the left testis in scrotal doppler ultrasound examination.

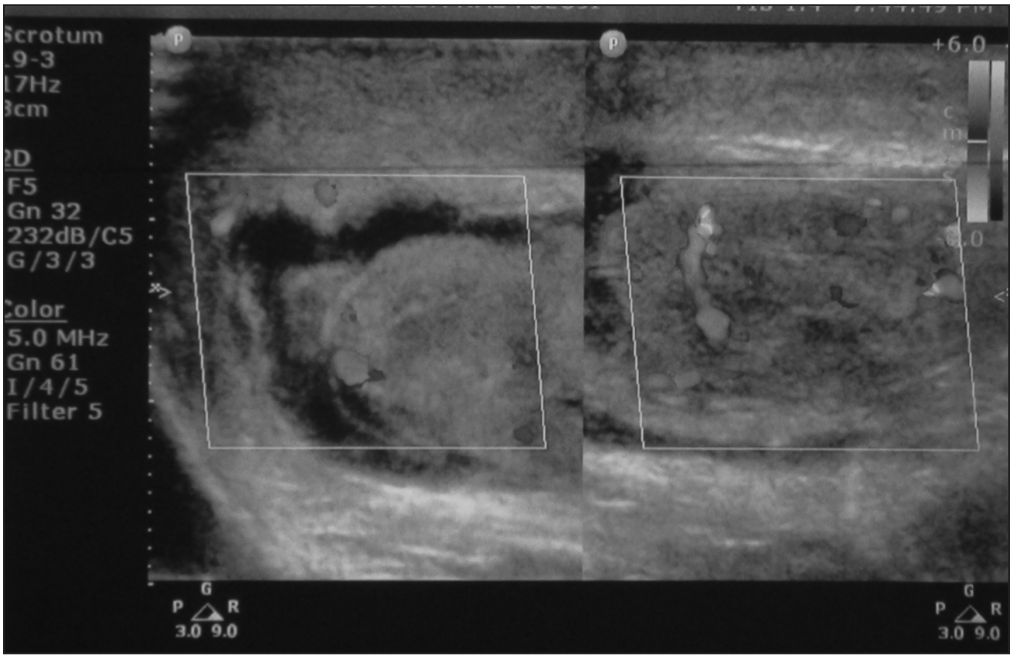

Figure 4.

Massive perivascular cell infiltrate composed of polymorphonuclear neutrophils (PMN) which was associated with extravasated erythrocytes and fibrinoid degeneration (leucocytoclastic vasculitis). H\&Ex400.

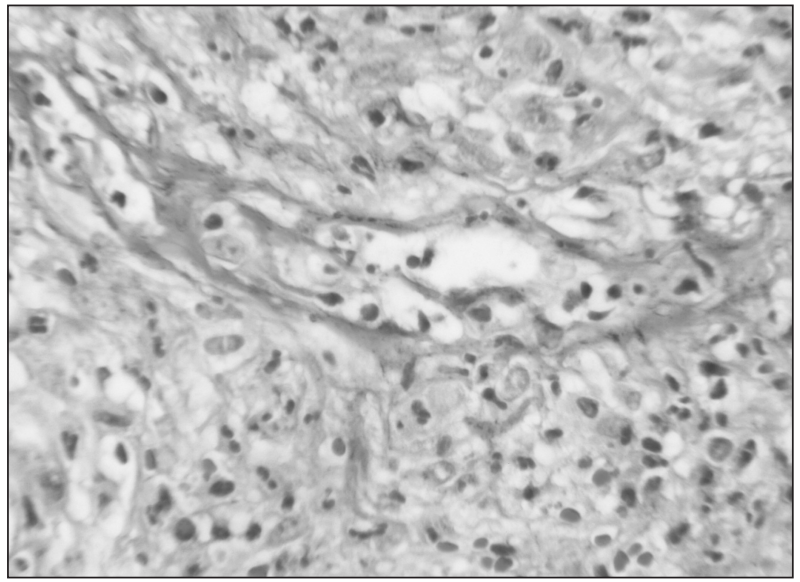

prednisolone was administered to treat the HSP orchiepididymitis. Scrotal swelling and purpuric rash subsided at $10^{\text {th }}$ day of the treatment and the child was discharged with a stable condition and was followed up two weeks later. Edema of the scrotum was diminished and purpuric rash was completely faded away, left testis was softened and regressed to normal volume and structure.

\section{Discussion}

Henoch- Schönlein purpura (HSP) is the most common vasculitis in children between 4 and 11 years of age and has an incidence of 14 in 100.000 population and usually occurs with a multi-organ involvement (1).

Typically skin (with a characteristic rash present in all patients), joints of arms and legs, gastrointestinal tract and kidneys are affected. Some males also present exter- 
nal genitalia involvement and/or acute scrotum, with skin petechiae of buttock, legs and infrequently of the upper torso and extremities.

Schönlein first described the combination of arthritis and acute purpura in children in 1837, and Henoch reported the manifestations of nephritis and abdominal pain in $1874(2,3)$. The etiology of HSP remains still unknown. However increased serum circulating immune complexes and deposition of IgA in the wall of capillaries are thought to be a cause of acute autoimmune leucocytoclastic vasculitis. IgA deposits can be found in both skin and renal biopsy. HSP is typically characterized by palpable nonthrombocytopenic purpura on initial clinical presentation and most frequently on the hips. Articular, renal and gastrointestinal (GI) involvement could be associated. The common GI features are abdominal pain (58\%), massive colorectal bleeding or occult blood loss (20\%). Major complications of abdominal involvement develop in $4.6 \%$ (1.3-13.6\%), of which intestinal perforation, intussusception, and infarction constitute the major surgical complications. Scrotal involvement of HSP usually results in pain, tenderness, swelling or discoloration of scrotum. Scrotal pain sometimes mimics testicular torsion to various degrees. Scrotal swelling and pain in HSP are 2 to 38 percent and the first case was reported by Allen et al in 1960 (4-6). Involvement of scrotum sometimes appears as scrotal skin edema and a simple purpuric rash without scrotal and testicular swelling. A correct medical history and a careful examination with imaging studies should be done in the presence of painful scrotal swelling associated with HSP because of mimicking testicular torsion. However testicular involvement of HSP and torsion of testis have been reported together (7). Therefore differential diagnosis of acute scrotum is a very important condition in order to avoid urgent surgical exploration of the testis (Table 1). Acute scrotum may be seen in all age groups but mostly seen in preschool and school age group children. At onset of scrotal pain and scrotal swelling have simple urinalysis, color-flow Doppler ultrasonography and radionucleide imaging are appropriate. Color-flow Doppler ultrasound yielded a sensivity and specificity of $89 \%$ and 100\% respectively, whereas the testicular radionucleide imaging yielded a specificity of 100\% (8-10). The Doppler ultrasonography reveals a good blood flow to the testes in acute scrotum with HSP syndrome whereas an ischemia of the testis at Doppler ultrasound is demonstrated when torsion occurs. Untreated testicular torsion causes ischemic damage and concequently disrupt the spermatogenetic function. Therefore torsion of testis is a true surgical emergency within 6 hours. Scrotal involvement of HSP mimicking testicular torsion is self-limited benign disease and responsive to corticosteroid and/or antibiotic therapy (11). In conclusion, acut scrotal pain in a male child should always be approached as an emergent condition and testicular torsion should be first kept in mind, but differential diagnosis of acute scrotum is considerably important for avoiding unnecessary surgical operation. Erythematous rash and acute painful swelling on the scrotum in addition to purpura of the lower extremities and hips should be warning symptoms of HSP orchiepydidimitis for dermatologists, pediatricians and urologists even if there is no other symptom of systemic involvement.
Table 1.

Differential diagnosis of the acute scrotum.

\begin{tabular}{|ll|}
\hline 1. Torsion & $\begin{array}{l}\text { Torsion of testis } \\
\text { Torsion of appendix testis/epididymis }\end{array}$ \\
\hline 2. Inflammation & $\begin{array}{l}\text { Epididymitis/orchitis (orchiepydidimitis) } \\
\text { Cellulitis } \\
\text { Vasculitis limited to skin/testis (HSP) }\end{array}$ \\
\hline 3. Trauma (hematoma) & \\
\hline 4. Tumor & \\
\hline 5. Idiopathic scrotal edema & \\
\hline
\end{tabular}

\section{References}

1. Palumbo E. Diagnosis of Henoch-Schonlein purpura in a child presenting with bilateral acute scrotum. Acta Biomed. 2009; 80:289-91.

2. Henoch EH. About a peculiar form of purpura. Am J Dis Child. 1974; 128:78-9.

3. Roberts PF, Waller TA, Brinker TM, et al. Henoch-Schönlein purpura: a review article. Siuth Med J. 2007; 100:821-824.

4. Kawasaki Y. The pathogenesis and treatment of pediatric HenochSchönlein purpura nephritis. Clin Exp Nephrol 2011; 15:648-57.

5. Allen D, Diamond LK, Howell DA. Anaphylactoid purpura in children (Schonlein-Henoch syndrome): review with a follow-up of the renal complications.AMA J Dis Child. 1960; 99:833-54.

6. Anil M, Aksu N, Kara OD, et al. Henoch-Schonlein purpura in children from western Turkey: a retrospective analysis of 430 cases. Turk J Pediat. 2009; 51:429-36.

7. Loh HS, Jalan OM. Testicular torsion in Henoch-Schonlein syndrome. Br Med J. 1974; 2:96-7.

8. Ha TS, Lee JS. Scrotal involvement in childhood HenochSchönlein purpura. Acta Paediatr 2007; 96:552-5.

9. Patiala B. Role of color doppler in scrotal lesions. Indian J Radiol Imaging. 2009; 19:187-90.

10. Saulsbury FT. Henoch-Schönlein purpura in children. Report of 100 patientsand review of the literature. Medicine. 1999; 78:395-409.

11. Davis JE, Silverman M. Scrotal emergencies. Emerg Med Clin North Am. 2011; 29:469-84.

\section{Correspondence}

Levent Verim, MD (Corresponding Author)

Urologist, Urology Department, Haydarpasa Numune Training Hospital Sircasaray sokak yenigun ap. 4/3 otagtepe kavac1k Beykoz 34810 Istanbul, Turkey

leventverim@hotmail.com

Filiz Cebeci, MD

Dermatologist, Dermatology Department,

Haydarpasa Numune Training Hospital, Istanbul, Turkey cebecifiliz@yahoo.com

M. Remzi Erdem, MD

Urology Resident, Urology Department,

Bezmi Alem University School of Medicine, Istanbul, Turkey remzierdem@gmail.com

Adnan Somay, MD

Pathologist, Department of Pathology,

Fatih Sultan Mehmet Research and Teaching Hospital, Istanbul, Turkey adnansomay@hotmail.com 